\title{
MANCHESTER
} 1824

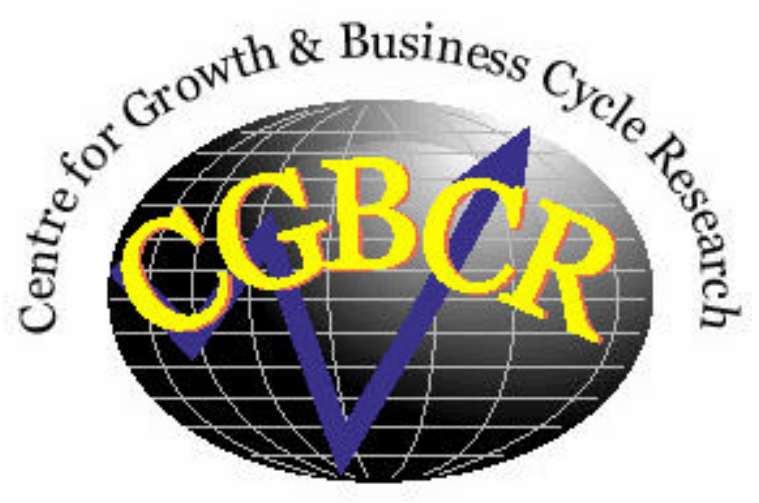

Discussion Paper Series

\section{Public Expenditures, Bureaucratic Corruption and Economic Development}

By

\author{
Keith Blackburn, \\ Niloy Bose and M. Emranul Haque
}

Centre for Growth and Business Cycle Research, Economic Studies,

University of Manchester, Manchester, M13 9PL, UK

May 2005

Number 053

Download paper from:

http://www.ses.man.ac.uk/cgbcr/discussi.htm 


\title{
Public Expenditures, Bureaucratic Corruption and Economic Development*
}

\author{
Keith Blackburn $\dagger_{\text {Niloy Bose }}^{\ddagger}$ and M. Emranul Haque ${ }^{\S}$
}

\begin{abstract}
This paper presents a dynamic general equilibrium analysis of public sector corruption and economic growth. In an economy with government intervention and capital accumulation, state-appointed bureaucrats are charged with the responsibility for procuring public goods which contribute to productive efficiency. Corruption arises because of an opportunity for bureaucrats to appropriate public funds by misinforming the government about the cost and quality of public goods provision. The incentive for each bureaucrat to do this depends on economy-wide outcomes which, in turn, depend on the behaviour of all bureaucrats. We establish the existence of multiple development regimes, together with the possibility of multiple, frequency-dependent equilibria. The predictions of our analysis accord strongly with recent empirical evidence on the causes and consequences of corruption in public office.
\end{abstract}

\section{Introduction}

Corruption has become the lead topic of debate among all major international development agencies. The World Bank, for example, has identified corruption as the single greatest obstacle to economic and social development, and has given priority to anti-corruption initiatives in its strategies

\footnotetext{
*The authors are grateful for the financial support of the ESRC (grant no.RES-000-220477). The usual disclaimer applies.

${ }^{\dagger}$ Centre for Growth and Business Cycle Research, Economic Studies, University of Manchester.

${ }^{\ddagger}$ Department of Economics, University of Wisconsin (Milwaukee).

${ }^{\S}$ Leverhulme Centre for Globalisation and Economic Policy, School of Economics, University of Nottingham.
} 
for improving the quality of governance. ${ }^{1}$ Of most concern is corruption within society's state institutions. Public officials - politicians, bureaucrats and legislators - hold unique positions of power and responsibility, the abuse of which can cause significant and long-lasting damage to many aspects of socio-economic development. Such abuse can manifest in a variety of ways including bribery, embezzlement, extortion and fraud - that may offer substantial personal gains at little risk of prosecution. Dishonest behaviour at one level in public office is often contagious and often supported by dishonest behaviour at other levels. For these and other reasons, public sector corruption is viewed as being especially harmful, especially pervasive and especially difficult to fight.

In spite of the above, there exists relatively little theoretical work on the macroeconomics of misgovernance. Two exceptions are the analyses of Ehrlich and Lui (1999) and Sarte (2000). ${ }^{2}$ The former develop a model in which opportunities to profit from bureaucratic malpractice create incentives for individuals to compete for the privelage of holding public office. These incentives lead to a diversion of resources away from growth-promoting activities (investments in human capital) towards power-seeking activities (investments in political capital). The latter constructs a framework in which rent-seeking bureaucrats restrict the entry of firms into the formal sector of the economy which has a better system of property rights and law enforcement than the informal sector. When the costs of informality are high, growth is reduced relative to the free-entry case. These analyses are revealing about the way in which corruption can have adverse effects on the prospective fortunes of an economy. They are less clear about why corruption may arise in the first place, why corruption may persist or decline over time, and why corruption may vary across otherwise similar economies. We seek to provide answers to these questions in the present paper.

\footnotetext{
${ }^{1}$ The connection between corruption and governance is two-way causal: corruption undermines good governance, while bad governance fosters corruption. For an appreciation of the importance of corruption to international policy makers, see the World Bank and IMF web-sites, www.worldbank.org/publicsector/anticorrupt and www.imf.org/external/np/exp/facts/gov. For some excellent reviews of the literature on corruption and development, see Bardhan (1997), Jain (2001), Rose-Ackerman (1999) and Tanzi (1998).

${ }^{2}$ See also Rivera-Batiz (2001) who studies the relationship between corruption, growth and financial liberalisation. In a purely static context, Acemoglou and Verdier $(1998,2000)$ conduct a general equilibrium analysis of how corruption may form part of an optimal allocation in which market failure is traded off against government failure. In contrast to this small body of macroeconomic research, the microeconomic literature on corruption is extensive (e.g., Banerjee 1997; Carrillo 2000; Klitgaard 1988, 1990; Rose-Ackerman 1975, 1978, 1999; Shleifer and Vishny 1993).
} 
The specific focus of our analysis is on corruption in public procurement. ${ }^{3}$ In general, corruption can affect both the volume and composition of public expenditures in ways that undermine development and foster inequality. Public funds earmarked for vital areas of spending may simply go missing and never be reclaimed. Purchases of goods and services may be based on who offers the best kickbacks, rather than who offers the best price-quality combination. Entire public programmes may be chosen more for their capacity to generate illegal income than for their potential to improve standards of living. Empirical studies suggest that corruption is, indeed, associated with a misallocation and misappropriation of public expenditures which are often inflated as a result. ${ }^{4}$ Mauro (1997) presents evidence that corruption distorts public expenditures away from growth-promoting areas (e.g., education and health) towards other types of project (e.g., large-scale infrastructure investment) that are less productivity-enhancing. In a similar vein, Tanzi and Davoodi (1997) find that corruption leads to a diversion of public funds to where bribes are easiest to collect, implying a bias in the composition of public spending towards low-productivity projects at the expense of value-enhancing investments. The same authors conclude that, as a result of corruption, the amount of public investment tends to rise, while the quality of this investment tends to fall. There is almost a limitless supply of anecdotal evidence as well. ${ }^{5}$ Abbott (1988) reports the instance in Haiti when a prominent member of the Duvalier regime had 150 kilometres of railtrack pulled up and sold for scrap metal, pocketing the proceeds for himself. Hardin (1993) recounts the case of the Turkwell Gorge Dam project in Kenya, the final cost of which was more than double the amount of initial

\footnotetext{
${ }^{3}$ Like the above, our analysis is concerned with the case in which civil servants, or bureaucrats, exploit their powers of discretion, delegated to them by the government, to further their own interests by indulging in illegal, or unauthorised, activities. This is known as bureaucratic corruption, as distinct from political and legislative corruption (e.g., Jain 2001).

${ }^{4}$ Empirical work on corruption has flourished over recent years due to the publication of several cross-country data sets that are widely regarded as providing reliable measures of corrupt activity. These data sets, or corruption indices, have been compiled by various international organisations (most notably Business International Corporation, Political Risk Services Incorporated and Transparency International) using questionnaire surveys sent to networks of correspondents around the world. The surveys are designed to produce a ranking of countries in terms of the extent to which corruption is perceived to exist (e.g., the extent to which public officials are believed to accept bribes, to make fraudulent demands and to embezzle public funds). For more detailed discussions of these indices, see Jain (1998), Tanzi and Davoodi (1997) and Treisman (2000).

${ }^{5}$ The single most extensive source of evidence is the World Bank's web-site, referred to in footnote 1. For a particularly perplexing account of the experiences of many African countries, see also www.freeafrica.org.
} 
estimates due to the recoupment of bribe payments by the French contractor. Rose-Ackerman (1999) tells of the millions of dollars of non-existent stationary that was "purchased" by the Government Press Fund in Malawi, and describes how telephone specifications in another African country contained the useless requirement that the equipment must be robust to freezing temperatures (a requirement that could be satisfied by only one telephone manufacturer from Scandinavia). These, and countless other, examples bear testimony to the problems that face many developing countries. The scale of the offences and the ingenuity of those behind them are often quite staggering, and it is difficult not to be shocked by the insidiousness of individuals in extracting public resources from an already deprived nation to which they, themselves, belong. ${ }^{6}$

The model that we use for our analysis describes an overlapping generations economy in which the government instructs bureaucrats to provide public goods that function as inputs to private production and that are financed from taxes on households. In accordance with the above, bureaucratic malfeasance results in public expenditures that are not only excessive but also misallocated. A public good yields productive services of either low-quality or high-quality, and is procured at either low-cost or high-cost. The true characteristics of goods are known only to bureaucrats, implying an informational asymmetry that may motivate corrupt behaviour. In particular, bureaucrats may be tempted to deceive the government by claiming to deliver goods of high-quality at high-cost when they are actually providing goods of low-quality at low-cost. By doing this, bureaucrats inflate (artificially) the amount of public funds that must be raised and allow themselves an opportunity to embezzle some of these funds. Such behaviour is costly for society because it reduces capital accumulation through which growth and development take place. ${ }^{7}$

\footnotetext{
${ }^{6}$ This is not to say that similar offences are never committed in developed economies. For example, Rose-Ackerman (1999) describes a recent episode in Italy (a country with a consistently high corruption rating) when the costs of several major construction projects fell dramatically after various anti-corruption investigations.

${ }^{7}$ Embezzlement - the theft by an individual of resources that he is supposed to administer - is an especially difficult offence to deal with when it entails the misappropriation of public funds. While everyone in society may be affected, the fact that no private property is stolen or exchanged means that individuals have no legal rights by which to protest and seek compensation. This type of non-collusive corruption may pose just as many problems as more collusive forms (where benefits accrue to all parties involved), and there is evidence that both types are pervasive in developing countries (e.g., Foellmi and Oechslin 2003). Indeed, in many of the most corrupt countries, embezzlement is a major aspect of public sector misconduct, often more important than bribery. As it happens, our model could be reformulated as one in which bribery, rather than embezzlement, is the means by which
} 
A key implication of our analysis is that the incentive for a bureaucrat to engage in corruption depends on economy-wide outcomes which, in turn, depend on the existing stock of capital and the behaviour of all other bureaucrats. This leads to the following observations. First, corruption and development are determined jointly in a relationship that is two-way causal. This relationship shows how the quality of governance not only influences, but is also influenced by, the level of economic activity. Empirical support for this can be found in a number of studies where it is estimated that a significant proportion of the variations in corruption indices can be explained by variations in per-capita income levels (e.g., Ades and Di Tella 1999; Fisman and Gatti 2002; Frechette 2001; Husted 1999; Montinola and Jackman 1999; Paldam 2002; Rauch and Evans 2000; Treisman 2000). Second, bureaucratic decision making entails strategic interactions that may give rise to multiple, frequency-dependent equilibria associated with different (high and low) incidences of corruption. In general, such non-uniqueness is explained by appealing to the idea that, for one reason or another, an individual is more likely to be corrupt if others are corrupt, and vice versa. ${ }^{8}$ This idea has been incorporated into several partial equilibrium models of corruption, typical of which are the frameworks of Andvig and Moene (1990) and Cadot (1987), where non-uniqueness arises because a bureaucrat's expected punishment for being corrupt is a decreasing function of the number of other corrupt bureaucrats. ${ }^{9}$ In a slightly different vein, Tirole (1996) shows how group reputation effects may lead to multiple equilibria that are history-dependent in the sense that good or bad behaviour in the past motivates good or bad behaviour in the present. Our own account of the phenoemena stands in contrast to these analyses and relates to the impact of corruption on aggregate economic outcomes that influence individual decision making. Ceteris paribus, the higher is the level of corruption the lower are the levels of wages and interest rates. Since incomes are lower as a result, a bureaucrat who is corrupt stands to lose less if he is caught so that the incentive to be corrupt is stronger. In this way, a bureaucrat's compliance in corruption may depend critically on the compliance of others - hence the possibility of contagious behaviour and,

bureaucrats extract resources. This would involve specifying a separate sector of producers from whom bureaucrats procure goods and with whom bureaucrats may conspire in deceiving the government. We choose the present formulation for simplicity.

${ }^{8}$ For example, the more corrupt people there are, the less might be the probability that each one of them will be caught, the less might by the penalty that each one of them will incur and the less might be the moral costs, or stigma, that each one of them feels.

${ }^{9}$ The incidence of crime has been explained in a similar way. In Sah (1991), for example, an individual is more (less) likely to engage in criminal activity if there are many (few) others engaged in such activity because the chances that he will be caught are lower (higher). 
with this, multiple equilibria. We emphasise that this is only a possibility in our model for there are circumstances where such behaviour disappears and a unique equilibrium exists. Significantly, these circumstances relate to the level of development. This is another distinguishing feature of our analysis. Up to now, the question of how an economy may move from one equilibrium to another has been addressed largely on the basis of comparative static exercises (i.e., studying the effects of exogenous changes in parameter values). In our case the selection of an equilibrium is partly endogenous, being linked to an economy's position along its capital accumulation path.

The above aspects of our model imply the existence of threshold effects and multiple development regimes that allow us to explain a number of empirical observations. By way of illustration, we present in Table 1 some summary statistics about corruption and development for four consecutive years using the World Bank's income classification of countries, together with the Corruption Perception Index (CPI) of Transparency International (the most widely-used measure of corruption). A compelling feature of the data is the much higher corruption rating of poor countries than rich countries throughout the period. This is indicative of the negative correlation between corruption and development that has been reported in many empirical studies (e.g., Gyimah-Brempong 2000; Keefer and Knack 1997; Knack and Keefer 1995; Li et al. 2000; Mauro 1995; Sachs and Warner 1997). ${ }^{10}$ Another notable feature - one that has received relatively little exposure - is the much greater diversity in corruption levels among middle-income countries, for which the range of the CPI is significantly larger than the range for either low-income or high-income countries. A comparison of the variance of the index across different income groups gives the same impression: the variance for the middle-income group is consistently higher than the variance for either the low- or high-income groups, in spite of the denser and larger sample of the middle-income group. The same picture emerges from looking at the coefficient of variation of the index and from the results of other investigations that we have undertaken. ${ }^{11}$

\footnotetext{
${ }^{10}$ In contrast, there is very little evidence to support the view (e.g., Huntington 1968; Leff 1964; Leys 1970) that corruption might actually be good for growth by helping to circumvent cumbersome regulations (red tape) in the bureacratic process. This is true even for countries that are reportedly mired with such regulations (e.g., Ades and Di Tella 1997; Mauro 1995; Kauffman and Wei 2000).

${ }^{11}$ In one of these we compute the rolling standard deviation of the index for each of the four periods, begining with the poorest country and ending with the richest. The typical pattern to emerge is one in which the standard deviation remains low to begin with (when only low-income countries are included), then gradually increases (as middle-income countries are added), and then finally falls again (with the introduction of high-income countries). In another analysis we examine the properties of the CPI, together with other
} 
The foregoing observations merit consideration and our analysis aims to provide an account of them. It does so on the basis of the following results: below some critical level of capital, there is a low development regime that displays a unique equilibrium in which the incidence of corruption is high; above some other critical level of capital, there is a high development regime that displays a unique equilibrium in which the incidence of corruption is low; and in between the two thresholds, there is an intermediate development regime that displays both types of equilibria. Thus our analysis is able to explain not only why corruption is higher in poor countries than in rich countries, but also why it is more varied among middle-income countries. Additionally, we establish the result that, depending on circumstances, transition between development regimes may or may not be feasible. In the case of the latter, the limiting outcome of the economy hinges crucially on initial conditions. Most notably, if the economy is poor and corrupt to begin with, then it will be destined to remain poor and corrupt unless fundamental changes take place. In this way, our analysis also provides an account of why poverty and corruption may co-exist as persistent phenomena, as they have clearly done so in many countries (e.g., Bardhan 1997; Sah 1988). ${ }^{12}$

The remainder of the paper is organised as follows. In Section 2 we describe the economic environment. In Section 3 we identify conditions under which an individual bureaucrat will be corrupt. In Section 4 we establish the existence of alternative equilibria. In Section 5 we analyse the implications for public expenditures and capital accumulation. In Section 6 we make a few concluding remarks.

\section{The Model}

Time is discrete and indexed by $t=0, . ., \infty$. There is a constant population of two-period-lived agents belonging to overlapping generations of dynastic families. Agents of each generation are divided into two groups of citizens private individuals (or households), of whom there are $m$, and public servants (or bureaucrats), of whom there are $n<m .^{13}$ All agents are risk neutral,

corruption indices (in particular, those of Business International Corporation and Political Risk Services Incorporated), in earlier years and again reach the same conclusion.

${ }^{12}$ It is certainly true that many of the most poor and corrupt countries of the past remain the most poor and corrupt countries of today. Examples include Bangladesh, Cameroon, India, Indonesia, Kenya, Nigeria, Pakistan and Uganda. According to the data from Transparency International, these belong to a set of nations that have displayed little, or no, improvement in their corruption and growth records since the early 1980s.

${ }^{13}$ We assume that agents are differentiated at birth according to their abilities and skills. A population of $m$ agents lack the skills necessary to become bureaucrats, while a 
working only when young and consuming only when old. Households work for firms in the production of output, while bureaucrats work for the government in the administration of public policy. Public policy consists of a programme of taxes and expenditures designed to make available public goods and services which contribute to the efficiency of output production. Corruption arises from the incentive of a bureaucrat to appropriate public funds by falsifying information to the government. We assume that a fraction, $\nu \in(0,1)$, of bureaucrats are corruptible in this way, while the remaining fraction, $1-\nu$, are non-corruptible, with the identity of a bureaucrat being unobservable by the government. ${ }^{14}$ Firms, of which there is a unit mass, hire labour from households and rent capital from all agents in perfectly competitive markets.

\subsection{The Private Sector}

Each firm combines $l_{t}$ units of labour with $k_{t}$ units of capital to produce $y_{t}$ units of output according to

$$
y_{t}=A\left(l_{t} K_{t}\right)^{\alpha} k_{t}^{1-\alpha} G^{\beta}, \quad A>0, \alpha, \beta \in(0,1)
$$

where $K_{t}$ denotes the aggregate stock of capital and $G$ denotes the aggregate quality of public goods and services. ${ }^{15}$ The firm hires labour at the competitively-determined wage rate $w_{t}$ and rents capital at the competitivelydetermined rental rate $r_{t}$. Profit maximisation yields $w_{t}=\alpha A l_{t}^{\alpha-1} k_{t}^{1-\alpha} K_{t}^{\alpha} G^{\beta}$ and $r_{t}=(1-\alpha) A l_{t}^{\alpha} k_{t}^{-\alpha} K_{t}^{\alpha} G^{\beta}$. In equilibrium $l_{t}=l$ (the fixed supply of

population of $n$ agents posess these skills. The latter are induced to become bureaucrats by an allocation of talent condition established below. Thus, as in other analyses (e.g., Ehrlich and Lui 1999; Sarte 2000), we abstract from issues relating to occupational choice. In doing so we are able to simplify the analysis by not having to consider possible changes in the size of the bureaucracy and possible changes in the level of corruption that may result from this.

${ }^{14}$ This assumption may be thought of as capturing differences in the propensities of bureaucrats to engage in corruption, whether due to differences in proficiencies at being corrupt or differences in moral attitudes towards being corrupt (e.g., Acemoglu and Verdier 2000; Besley and McLaren 1993; Tirole 1996). The main purpose of the assumption is to allow us to determine the wages of bureaucrats in a relatively straightforward way that does not demand additional assumptions about how public sector pay is determined. In fact, all we need for this purpose is that there be at least one bureaucrat who is non-corruptible - all other bureaucrats may well be potential transgressors.

${ }^{15} \mathrm{As}$ in other models of growth, we incorporate the aggregate stock of capital to capture the positive externalities associated with learning-by-doing (e.g., Romer 1986). As in other models as well, we treat public goods as providing productive services which raise the efficiency of other inputs in private production (e.g., Barro 1990). 
labour) and $k_{t}=K_{t}$ so that we may write these conditions as

$$
\begin{gathered}
w_{t}=\alpha A l^{\alpha-1} G^{\beta} k_{t} \equiv w\left(k_{t}\right), \\
r_{t}=(1-\alpha) A l^{\alpha} G^{\beta} \equiv r
\end{gathered}
$$

Thus the equilibrium wage is proportional to the capital stock, while the equilibrium interest rate is constant.

Each young household of generation $t$ is endowed with $\lambda>1$ units of labour (implying $l=\lambda m$ ) which it supplies inelastically to firms in return for a wage of $w_{t}$. Each household also receives an inheritance of $b_{t}$ and is liable to pay taxes of $\tau_{t}$. A household saves its entire net income at the market rate of interest $r$ to obtain a final level of wealth of $(1+r)\left(\lambda w_{t}-\tau_{t}+b_{t}\right)$ when it reaches old-age. It then consumes part of this wealth and bequeaths the remainder to its own offspring. The lifetime utility of a household is given by $u_{t}=(1+r)\left(\lambda w_{t}-\tau_{t}+b_{t}\right)-b_{t+1}+v\left(b_{t+1}\right)$, where $(1+r)\left(\lambda w_{t}-\tau_{t}+\right.$ $\left.b_{t}\right)-b_{t+1}$ is consumption and $v(\cdot)$ is a strictly concave function that satisfies the usual Inada conditions. ${ }^{16}$ It follows that utility is maximised by setting $v^{\prime}(\cdot)=1$, implying an optimal fixed size of bequest from one generation to the next: that is, $b_{t+1}=b$ for all $t$. Changes in household incomes are therefore governed by changes in wages and changes in taxes. ${ }^{17}$

\subsection{The Public Sector}

The objective of the government is to provide public goods and services which function as inputs to private production. The government demands $g$ amount of these goods and delegates the task of procuring them to bureaucrats, while running a continuously balanced budget. ${ }^{18}$ In return for his services, a bureaucrat is paid a salary which is determined as follows. Any bureaucrat (whether corruptible or non-corruptible) can work for a firm to receive an income equal to the wage paid to households. Any bureaucrat who is willing to accept a salary less than this wage must be expecting to receive compensation through some form of malpractice and is therefore immediately identified as being corrupt. We assume that a bureaucrat who is

\footnotetext{
${ }^{16}$ This function captures the 'warm-glow', or 'joy-of-giving' motive for making bequests. We choose this simple way of modelling altruism since the main role of bequests in our model is merely to ensure the existence of a non-degenerate steady state equilibrium along a linear (rather than concave) capital accumulation path.

${ }^{17}$ Appropriate restrictions on parameter values ensure that the after-tax income of a household is always positive.

${ }^{18}$ Bureaucrats are also responsible for the collection of taxes, an activity that may also be open to abuse in the form of bribery and tax evasion. This does not arise in our model because all households have the same income and are subject to same tax liability.
} 
discovered to be corrupt is fined by an amount at least equal to his salary (i.e., he is dismissed without pay) and that any remaining (illegal) income in his possession is strictly less than the wage that he would have received by working for firms. ${ }^{19}$ Given this, then no corruptible bureaucrat would ever reveal himself in the way described above. As such, the government can minimise its labour costs, while ensuring complete bureaucratic participation, by setting the salaries of all bureaucrats equal to the wage paid by firms to households. ${ }^{20}$ Against this background, the government keeps a check on bureaucratic behaviour using an imprecise monitoring technology. This technology implies that a bureaucrat who is corrupt faces a probability, $p \in(0,1)$, of avoiding detection, and a probability, $1-p$, of being found out. For convenience, we assume that monitoring is costless. ${ }^{21}$

Each bureaucrat is charged with the responsibility for procuring $\frac{g}{n}$ units of public goods using whatever public funds are allocated to him. A public good may be of either high-quality or low-quality and may be procured at either high-cost or low-cost. One unit of a high-quality good yields 1 unit of productive service, while one unit of a low-quality good yields $\gamma<1$ units of productive service. The cost of the former is a random variable which we assume to be identically and independently distributed, and to take the value of 1 unit of output with probability $q \in(0,1)$ and the value of $\phi>1$ units of ouptut with probability $1-q$. The cost of the latter is $\theta<1$ units of output with certainty. ${ }^{22}$ Corruption is made possible due to informational asymmetries between bureaucrats and the government as a consequence of the delegation of duties by the latter to the former. It is bureaucrats who evaluate public goods in terms of their cost and quality, and who supply the government with information on which to base decisions. By falsifying this information, a bureaucrat may be able to enrich himself

\footnotetext{
${ }^{19}$ As we shall see, the latter assumption amounts merely to a restriction on initial conditions - in particular, the initial capital stock which determines the initial wage. The assumption would be irrelevant if one was to suppose that the bureaucrat is fined the full amount of his legal and illegal income.

${ }^{20}$ This has the same interpretation as the allocation of talent condition in Acemoglou and Verdier (2000). The government cannot force any of the $n$ potential bureaucrats to actually take up public office, but it is able to induce all of them to do so by paying what they would earn elsewhere.

${ }^{21}$ The model could be extended straightforwardly to allow for costly monitoring without altering its main implications. To a large extent, our results would be strengthened in the sense that there would be an additional loss of resources from corruption.

${ }^{22}$ As indicated earlier, the effect of corruption in our model is that public goods are provided at a lower overall quality but greater total expense. The latter result is due to the variability in cost of high-quality goods. The former result prevails regardless of this assumption.
} 
through the appropriation of public funds. More precisely, we assume that only bureaucrats are informed about the true cost and quality of public goods. All that the government knows is that a public good may be of highquality or low-quality, and that the per unit cost of any high-quality good is 1 or $\phi$. Given this state of affairs, the government instructs each bureaucrat to maximise public good quality per unit of expenditure. For a high-quality good, there is an upper value and a lower value of this, as given by 1 and $\frac{1}{\phi}$, respectively. For a low-quality good, the value is $\frac{\gamma}{\theta}$. We confine our attention to the case in which $\frac{1}{\phi}>\frac{\gamma}{\theta}$. Under such circumstances, the government will always demand high-quality goods, whatever their alleged cost.

A bureaucrat, when young, is endowed with one unit of labour which he supplies inelastically to the government to earn a salary of $w_{t}$. For simplicity, we assume that bureaucrats have no other source of legal income and are exempt from paying any taxes. ${ }^{23}$ Like all households, all bureaucrats save their entire income at the rate of interest $r$ in order to finance retirement consumption. By definition, a bureaucrat who is not corrupt abides fully by the government's instructions for providing public goods. Such a bureaucrat procures $\frac{g}{n}$ units of goods at a true total cost of $\frac{g}{n}$ or $\phi\left(\frac{g}{n}\right)$ and a true total quality of $\frac{g}{n}$. The final wealth of a non-corrupt bureaucrat is $(1+r) w_{t}$. In contrast, a bureaucrat who is corrupt pursues his own hidden agenda which conflicts with the interests of the government. Such a bureaucrat engages in deception by procuring low-quality public goods at low-cost, while claiming that the goods are of high-quality and high-cost. Although the quantity of each good is still $\frac{g}{n}$, the quality is only $\gamma\left(\frac{g}{n}\right)$, and although the bureaucrat claims $\phi\left(\frac{g}{n}\right)$ in public funds, he spends only $\theta\left(\frac{g}{n}\right)$. Thus $(\phi-\theta)\left(\frac{g}{n}\right)$ is the amount of funds that a bureaucrat may be able to embezzle by misleading the government. In general, corrupt individuals may try to remain inconspicuous by concealing their illegal income, by investing this income differently from legal income and by altering their patterns of expenditure. For the purposes of the present analysis, we make the simple assumption that a bureaucrat who is corrupt must store his illegal income in hiding (rather than invest it in capital) if he is to stand any chance of not being caught. In doing this, the bureaucrat is assured of retaining his illegal income whether he is caught or not, and of losing only his legal income in the event of the former. ${ }^{24}$ Accordingly, the bureaucrat's final wealth is $(1+r) w_{t}+(\phi-\theta)\left(\frac{g}{n}\right)$ with probability $p$, and $(\phi-\theta)\left(\frac{g}{n}\right)$ with probability $1-p$, implying an expected wealth of $p(1+r) w_{t}+(\phi-\theta)\left(\frac{g}{n}\right)$.

\footnotetext{
${ }^{23}$ The fact that bureaucrats have only one unit of labour (as opposed to $\lambda$ units) may be used to justify this assumption.

${ }^{24} \mathrm{An}$ alternative way of modelling this is to assume that bureaucrats must consume their illegal income immediately if they are to stand any chance of avoiding detection.
} 


\section{The Incentive to be Corrupt}

A corruptible bureaucrat will embezzle public funds if his expected payoff from doing so is no less than his payoff from not doing so. From the preceding analysis, we may state this condition as $p(1+r) w_{t}+(\phi-\theta)\left(\frac{g}{n}\right) \geq(1+r) w_{t}$, or

$$
\frac{(\phi-\theta) g}{n} \geq(1-p)(1+r) w_{t} .
$$

Intuitively, a bureaucrat is more likely to be corrupt the more he stands to gain in illegal income and the less he expects to lose in legal income if he is caught. The key feature of the condition in (4) is that it depends on the economy-wide variables $r$ and $w_{t}$. Both of these variables - the interest rate and the wage rate - are determined by current events in the economy. In particular, they are both functions of the aggregate level of corruption at time $t$, as we shall see below. This means that the motivation for each corruptible bureaucrat to be corrupt depends on the number of other such bureaucrats who are expected to be corrupt. Consequently, bureaucratic behaviour entails strategic interactions which may result in multiple, frequency-dependent equilibria. We begin to explore this possibility by first studying the individual incentives of a corruptible bureaucrat to engage in corruption under two opposite scenarios - one in which no other corruptible bureaucrat is corrupt and the other in which all other corruptible bureaucrats are corrupt. In doing so, we make use of the results in (2) and (3), where $G$ is recalled to measure the aggregate quality, or total productive services, of public goods.

For the case in which no corruptible bureaucrat is corrupt, $G$ is given by $\widehat{G}=g$ since all bureaucrats procure only high-quality public goods (yielding total services of $\left.n\left(\frac{g}{n}\right)\right)$. Under such circumstances, (4) becomes

$$
\frac{(\phi-\theta) g}{n} \geq(1-p)(1+\widehat{r}) \widehat{w}_{t} \equiv \widehat{h}\left(k_{t}\right)
$$

where

$$
\begin{gathered}
\widehat{r}=(1-\alpha) A l^{\alpha} g^{\beta}, \\
\widehat{w}_{t}=\alpha A l^{\alpha-1} g^{\beta} k_{t} \equiv \widehat{w}\left(k_{t}\right) .
\end{gathered}
$$

The expression in (5) is the condition for an individual corruptible bureaucrat to be corrupt, given that no other corruptible bureaucrat is corrupt.

For the case in which all corruptible bureaucrats are corrupt, $G$ is determined as $\widetilde{G}=(1-\nu+\gamma \nu) g$ since only non-corrupt bureaucrats procure high-quality public goods (yielding total services of $(1-\nu) n\left(\frac{g}{n}\right)$ ), while corrupt bureaucrats procure low-quality public goods (yielding total services of 
$\left.\nu n \gamma\left(\frac{g}{n}\right)\right)$. As such, (4) becomes

$$
\frac{(\phi-\theta) g}{n} \geq(1-p)(1+\widetilde{r}) \widetilde{w}_{t} \equiv \widetilde{h}\left(k_{t}\right)
$$

where

$$
\begin{gathered}
\widetilde{r}=(1-\alpha) A l^{\alpha}(1-\nu+\gamma \nu)^{\beta} g^{\beta}, \\
\widetilde{w}_{t}=\alpha A l^{\alpha-1}(1-\nu+\gamma \nu)^{\beta} g^{\beta} k_{t} \equiv \widetilde{w}\left(k_{t}\right) .
\end{gathered}
$$

The expression in (8) is the condition for an individual corruptible bureaucrat to be corrupt, given that all other corruptible bureaucrats are corrupt.

Observe that, since $1-\nu+\gamma \nu<1$, (6) and (9) imply $\widetilde{r}<\widehat{r}$, while (7) and (10) imply $\widetilde{w}(\cdot)<\widehat{w}(\cdot)$ : that is, for any given stock of capital, $k_{t}$, interest rates and wages are lower under corruption than under non-corruption. This follows from the fact that corruption reduces the aggregate quality of public goods, $\widetilde{G}<\widehat{G}$. In doing so, it also reduces the productivity of other inputs (capital and labour) in output production.

\section{Equilibria}

The foregoing analysis sets out the conditions for an individual corruptible bureaucrat to be either corrupt or non-corrupt, given that all other corruptible bureaucrats are either corrupt or non-corrupt. The analysis also reveals the extent to which the aggegate level of corruption influences aggregate economic outcomes - in particular, interest rates, wages and the quality of public goods provision. We now proceed to study how the incidence of corruption, itself, is determined. As we shall see, whether or not corruption forms part of an equilibrium depends on the level of development of the economy. In this way, our model predicts a relationship between corruption and development that is fundamentally two-way causal.

The crucial conditions for determining equilibrium behaviour are given in (5) and (8). Note that both $\widehat{h}(\cdot)$ and $\widetilde{h}(\cdot)$ are increasing monotonically (linearly) in $k_{t}$. Note also that $\widehat{h}(\cdot)>\widetilde{h}(\cdot)$ for all $k_{t}$. Given these observations, we may identify two critical levels of capital, $k_{1}^{c}$ and $k_{2}^{c}$, in accordance with the following.

Definition $1 k_{1}^{c}$ is the unique value of $k_{t}$ which satisfies $\widehat{h}\left(k_{1}^{c}\right)=\frac{(\phi-\theta) g}{n}$ such that (i) $\widehat{h}(\cdot)<\frac{(\phi-\theta) g}{n}$ for all $k_{t}<k_{1}^{c}$, and (ii) $\widehat{h}(\cdot)>\frac{(\phi-\theta) g}{n}$ for all $k_{t}>k_{1}^{c}$.

Definition $2 k_{2}^{c}$ is the unique value of $k_{t}$ which satisfies $\widetilde{h}\left(k_{2}^{c}\right)=\frac{(\phi-\theta) g}{n}$ such that (i) $\widetilde{h}(\cdot)<\frac{(\phi-\theta) g}{n}$ for all $k_{t}<k_{2}^{c}$, and (ii) $\widetilde{h}(\cdot)>\frac{(\phi-\theta) g}{n}$ for all $k_{t}>k_{2}^{c}$. 
Evidently, $k_{1}^{c}<k_{2}^{c}$. These threshold levels of capital represent boundaries between regions where the incentive conditions in (5) and (8) are either satisfied or violated. We are now in a position to establish some key results which we illustrate in Figure 1.

Proposition 1 For $k_{t}<k_{1}^{c}$, there exists a unique equilibrium in which all corruptible bureaucrats are corrupt.

Proof. Suppose that $k_{t}<k_{1}^{c}$. Then $\widetilde{h}(\cdot)<\frac{(\phi-\theta) g}{n}$ and $\widehat{h}(\cdot)<\frac{(\phi-\theta) g}{n}$, implying that it pays each corruptible bureaucrat to be corrupt, irrespective of whether other corruptible bureaucrats are corrupt or non-corrupt. The case in which all such bureaucrats are corrupt is an equilibrium outcome since none of them has an incentive to deviate from corrupt behaviour. Conversely, the case in which all such bureaucrats are non-corrupt is not an equilibrium outcome since each of them has an incentive to deviate from non-corrupt behaviour.

This result demonstrates that low levels of development are associated with high (maximum) levels of corruption.

Proposition 2 For $k_{t}>k_{2}^{c}$, there exists a unique equilibrium in which no corruptible bureaucrat is corrupt.

Proof. Suppose that $k_{t}>k_{2}^{c}$. Then $\widehat{h}(\cdot)>\frac{(\phi-\theta) g}{n}$ and $\widetilde{h}(\cdot)>\frac{(\phi-\theta) g}{n}$, implying that it pays each corruptible bureaucrat to be non-corrupt, irrespective of whether other corruptible bureaucrats are non-corrupt or corrupt. The case in which all such bureaucrats are non-corrupt is an equilibrium outcome since none of them has an incentive to deviate from non-corrupt behaviour. Conversely, the case in which all such bureaucrats are corrupt is not an equilibrium outcome since each of them has an incentive to deviate from corrupt behaviour.

This result demonstrates that high levels of development are associated with low (zero) levels of corruption.

Proposition 3 For $k_{t} \in\left(k_{1}^{c}, k_{2}^{c}\right)$, there are multiple equilibria in which all corruptible bureaucrats are either corrupt or non-corrupt.

Proof. Suppose that $k_{t} \in\left(k_{1}^{c}, k_{2}^{c}\right)$. Then $\widetilde{h}(\cdot)<\frac{(\phi-\theta) g}{n}$ but $\widehat{h}(\cdot)>\frac{(\phi-\theta) g}{n}$, implying that it pays each corruptible bureaucrat to be either corrupt or noncorrupt, depending on whether other corruptible bureaucrats are corrupt 
or non-corrupt. The case in which all such bureaucrats are corrupt is an equilibrium outcome since none of them has incentive to deviate from corrupt behaviour. Likewise, the case in which all such bureaucrats are non-corrupt is also an equilibrium outcome since none of them has an incentive to deviate from non-corrupt behaviour.

This result demonstrates that intermediate levels of development may be associated with either low or high levels of corruption.

Based on the foregoing analysis, we are led to distinguish between three types of development regime for the economy. The first - a low development regime - is one in which the incidence of corruption is always at its maximum for any given level of capital below the lower threshold level, $k_{1}^{c}$. The second - a high development regime - is one in which the incidence of corruption is always at its minimum for any given level of capital above the upper threshold level, $k_{2}^{c}$. And the third - an intermediate development regime - is one in which the incidence of corruption may be either at its maximum or at its minimum for any given level of capital between the two thresholds. The intuition is as follows. Each corruptible bureaucrat chooses to be corrupt or non-corrupt according to whether the condition in (4) is satisified or violated. This condition depends on economy-wide outcomes (wages and interest rates) which, in turn, depend on the existing aggregate stock of capital (measuring the level of development) and the total quality of public goods provision (reflecting the behaviour of all other bureaucrats). At sufficiently low or sufficiently high levels of development, a bureaucrat's incentive to behave in one way or another is unaffected by how other bureaurcrats are behaving: what matters most is the level of development, itself. For capital stocks below $k_{1}^{c}$, wages are always low enough to ensure that the condition in (4) is satisfied. As such, a corruptible bureaucrat will always be corrupt, irrespective of what others around him may be doing. Since this is true for all such bureaucrats, then the only equilibrium from which there is no incentive to deviate is one in which corruption is the unique choice of strategy. Conversely, for capital stocks above $k_{2}^{c}$, wages are always high enough such that the condition in (4) is violated. In this case a corruptible bureaucrat will never be corrupt, regardless of what others may be up to. Being true for all such bureaucrats, this means that the only equilibrium from which defection will not occur is one in which non-corruption is the singular choice of action. In contrast to these scenarios, a bureaucrat's incentive to transgress at intermediate stages of development depends critically on the exploits of others. For any given stock of capital between $k_{1}^{c}$ and $k_{2}^{c}$, the condition in (4) is satisfied if corruption is widespread but is violated if corruption is absent. A corruptible bureaucrat will now be corrupt or non-corrupt according to whether other 
such bureaucrats are corrupt or non-corrupt. Consequently, there are two candidate equilibria that are frequency-dependent and that are equally likely to arise. As indicated earlier, our explanation for this non-uniqueness is different from other accounts and relates to the effects of corruption on both wages and interest rates. These variables determine the legal incomes of bureaucrats and are increasing functions of the quality of public goods provision. The lower is this quality (i.e., the more corruption there is) the lower is the amount of income that a corrupt bureaucrat stands to lose if he is caught and so the lower is the expected punishment for being corrupt. In this way, a bureaucrat's expected gain from wrong-doing depends positively on the number of other wrong-doers - hence the possibility of multiple equilibria. As we also indicated, our analysis has the further distinction of showing how this possibility is inextricably linked to an economy's stage of development: only at intermediate stages is behaviour contagious; at other stages - both lower and higher - individuals act independently of others.

The predictions of our model are consistent with the empirical observations highlighted earlier: the unique equilibrium at low levels of development accords with the situation of most poor countries in which the incidence of corruption is generally high; the unique equilibrium at high levels of development matches the position of most rich countries in which the incidence of corruption is typically low; and the multiplicity of equilibria at intermediate levels of development fits with the diverse experiences of middle-income countries in which the incidence of corruption is varied. Like other analyses, we are able to account for a broadly negative relationship between corruption and development. Unlike other analyses, we are also able to explain why this relationship may be rather tenuous in some circumstances. In fact, the results obtained above do not exhaust the full set of outcomes that are possible at intermediate stages of development. In studying this case, we have confined our attention to the two pure strategy equilibria that manifest at low and high stages of development - that is, equilibria in which all corruptible bureaucrats behave in exactly the same way. Yet there is also a mixed strategy equilibrium in this case - that is, an equilibrium in which bureaucratic behaviour is heterogeneous. More precisely, this equlibrium entails a fraction, $\eta \in(0,1)$, of corruptible bureaucrats who are corrupt and a remaining fraction, $1-\eta$, of such bureaucrats who are not corrupt. We show this in an Appendix by establishing that, for each $k_{t} \in\left(k_{1}^{c}, k_{2}^{c}\right)$, there exists an $\eta$ such that the incentive condition in (4) holds with equality. This means that a middle-income country could find itself in any one of three possible equilibria with an incidence of corruption that is high, low or somewhere in between. The idea that, for some countries, development might be associated with an increase in corruption has been argued by a number of observers 
who point to the potential for modernisation and liberalisation to create new incentives and new opportunities for agents to engage in corrupt practices. The experiences of several transition economies appear to bear testimony to this (e.g., Bardhan 1997; Basu and Li 1998).

\section{Public Finance and Capital Accumulation}

We have seen how the incidence of corruption depends on the level of development. We have yet to study how the development process, itself, is affected by corrupt activity. This process is described by the path of capital accumulation, obtained from the equilibrium condition that the total demand for capital is equal to the total supply of savings. To determine how corruption affects savings, it is necessary to consider how corruption affects public finances since the state of the government's balance sheet dictates the level of taxes required to maintain budget balance. In conducting our analysis, we appeal to the law of large numbers to replace probabilistic events at the individual level by actual outcomes at the aggregate level. Thus $p(1-p)$ is understood to be a measure of corrupt bureaucrats who succeed (fail) in their illegal profiteering, while $q(1-q)$ is understood to be a measure of high-quality public goods that have low (high) cost.

Consider the case in which no corruptible bureaucrat is corrupt. Each and every bureaucrat, of whom there are $n$, claims the truthful amount of public funds that he requires to procure high-quality public goods. The total value of claims for low-cost procurement is $n q\left(\frac{g}{n}\right)$, and the total value of claims for high-cost procurement is $n(1-q) \phi\left(\frac{g}{n}\right)$. Accordingly, $[q+(1-q) \phi] g=\Phi g$ is the overall amount of resources that the government allocates to public goods provision. The government also incurs expenditures of $n \widehat{w}_{t}$ on bureaucrats' salaries. On the revenue side, the government receives tax payments from households of $m \widehat{\tau}_{t}$. The value of $\widehat{\tau}_{t}$ is determined from the government's budget constraint as

$$
m \widehat{\tau}_{t}=\Phi g+n \widehat{w}_{t} .
$$

Total savings in the economy comprise the savings of households, $m\left(\lambda \widehat{w}_{t}-\right.$

$\left.\tau_{t}+b\right)$, plus the savings of bureaucrats, $n \widehat{w}_{t}$. Using (7) and (11), it follows that capital accumulation takes place according to

$$
\begin{aligned}
\widehat{k}_{t+1} & =l \widehat{w}_{t}-\Phi g+m b \\
& =\alpha A l^{\alpha} g^{\beta} k_{t}-\Phi g+m b \equiv \widehat{f}\left(k_{t}\right) .
\end{aligned}
$$

Consider, next, the case in which all corruptible bureaucrats are corrupt. These bureaucrats, of whom there are $\nu n$, make bogus claims on public funds 
by pretending to procure high-quality public goods at high-cost (when the opposite is true). The total value of these claims is $\operatorname{vn} \phi\left(\frac{g}{n}\right)$. Non-corruptible bureaucrats, of whom there are $(1-\nu) n$, behave truthfully as above, claiming $(1-\nu) n q\left(\frac{g}{n}\right)$ and $(1-\nu) n q \phi\left(\frac{g}{n}\right)$ in public funds. Accordingly, $\{(1-\nu)[q+(1-$ q) $\phi]+\nu \phi\} g=[\Phi+q \nu(\phi-1)] g$ is the aggregate amount of resources that the government now allocates to public goods provision. Added to this is $n \widetilde{w}_{t}$, expenditures on bureaucrats' salaries. Revenues for the government comprise the tax income from households, $m \widetilde{\tau}_{t}$, plus the value of fines imposed on corrupt bureaucrats who are caught, $(1-p) \nu n \widetilde{w}_{t}$. From the government's budget constraint, the value of $\widetilde{\tau}_{t}$ is deduced as

$$
m \widetilde{\tau}_{t}=[\Phi+q \nu(\phi-1)] g+[1-(1-p) \nu] n \widetilde{w}_{t} .
$$

As above, total savings by households amount to $m\left(\lambda \widehat{w}_{t}-\tau_{t}+b\right)$. Total savings by bureaucrats consist of the savings by non-corruptible bureaucrats, $(1-\nu) n \widetilde{w}_{t}$, plus the savings of corruptible bureaucrats, $p \nu n \widetilde{w}_{t}$. Using (10) and (13), we may write the capital accumulation process in this case as

$$
\begin{aligned}
\widetilde{k}_{t+1} & =l \widetilde{w}_{t}-[\Phi+q \nu(\phi-1)] g+m b \\
& =\alpha A l^{\alpha}(1-\nu+\gamma \nu)^{\beta} g^{\beta} k_{t}-[\Phi+q \nu(\phi-1)] g+m b \equiv \widetilde{f}\left(k_{t}\right) .
\end{aligned}
$$

Assuming that $\alpha A l^{\alpha} g^{\beta} \in(0,1)$ and $m b>[\Phi+q v(\phi-1)] g$, both of the transitions paths in (12) and (14) exhibit stationary points associated with the steady state levels of capital $\widehat{k}^{*}=\frac{m b-\Phi g}{1-\alpha A l^{\alpha} g^{\beta}}$ and $\widetilde{k}^{*}=\frac{m b-[\Phi+q \nu(\phi-1)] g}{1-\alpha A l^{\alpha}(1-\nu+\gamma \nu)^{\beta} g^{\beta}}$, respectively. Evidently, $\widetilde{k}^{*}<\widehat{k}^{*}$ which follows from the fact that, for any given $k_{t}, \widetilde{f}(\cdot)<\widehat{f}(\cdot)$. Thus capital accumulation is lower under corruption than under non-corruption. There are two reasons for this. First, by reducing the total quality of public goods, corruption produces a fall in the productivity of labour, a fall in wages and a fall in savings. Second, by raising the total cost of public goods, corruption leads to greater public expenditures which also results in lower savings. ${ }^{25}$ In short, corruption affects both the quality and quantity of public spending in ways that compromise growth. This spending is not only misallocated (towards low-quality public goods) but is also inflated (by an artificial amount). This is another prediction of the model that concurs with empirical observation.

\footnotetext{
${ }^{25}$ Observe from (11) and (13) that taxes may be higher or lower under corruption than under non-corruption. This is because corruption, while resulting in greater public expenditures, leads to lower payment of salaries to bureaucrats (since some bureaucrats are dismissed from their jobs). Whether corruption exists or not, bureaucrats' salaries do not contribute to aggregate savings since they are completely offset by the taxes used to pay for them. Over and above this, taxes fund public expenditures which are higher under corruption.
} 
As well as accounting for cross-country differences in corruption, our analysis is able to explain why some countries may become saddled with persistent poverty and misgovernance. We illustrate this in Figure 2 which depicts the two development paths, $\widehat{f}(\cdot)$ and $\widetilde{f}(\cdot)$, together with the two threshold levels of capital, $k_{1}^{c}$ and $k_{2}^{c}$, for a particular configuration of parameter values. The economy is on the low development path, $\widetilde{f}(\cdot)$, for $k_{t}<k_{1}^{c}$, the high development path, $\widehat{f}(\cdot)$, for $k_{t}>k_{2}^{c}$, and either of the paths for $k_{t} \in\left(k_{1}^{c}, k_{2}^{c}\right)$. At the steady state level of capital $\widetilde{k}^{*}$, there is a poverty trap equilibrium: if the economy is poor and corrupt to begin with (e.g., if its initial capital stock is $k_{0}$ ), then it will be destined to remain poor and corrupt unless there is a radical turn of events to dictate otherwise. One such event is a windfall increase in the stock of capital that produces a leap over the lower threshold, $k_{1}^{c}$. Another is a change in the value of some key parameter that alters the transition function and/or the threshold, itself, such that $k_{1}^{c}<\widetilde{k}^{*}$. Even in these instances, however, there is no guarantee that the upper critical boundary, $k_{2}^{c}$, will be breached, in which case the economy will have just as much chance of settling in a good equilibrium as settling in a bad equilibrium. In addition, for a given distribution of economies below $k_{1}^{c}$, it is those in the upper tail (i.e., close to $k_{1}^{c}$ ) that are most likely to be affected, while those in the lower tail remain as they are. For these reasons, we are led to conclude that the divisions between poor and rich, corrupt and non-corrupt, countries are unlikely to vanish quickly, if at all.

\section{Final Remarks}

In seeking to understand how countries develop (or not), economists have become increasingly aware of the need to integrate the economic, social and political aspects of individual decision making, policy formulation and institutional design. There has also been growing recognition that many issues in development are difficult, if not impossible, to address without departing from the standard economic paradigm of honest, law-abiding agents whose pursuit of what is best for themselves entails no malevolence towards others. To many observers, there is a much harsher, more cynical reality, where agents are often devious, predatory and even cruel. When holders of public office are like this, the consequences can be particularly devastating and tragic. Corruption on the part of public officials may mean a world of difference between what policies are good for a nation and what policies are actually implemented. The latter may have much less to do with the promotion of growth and reduction of poverty, and much more to do with the personal enrichment of a privelaged few following their own hidden agenda. 
In spite of the above, there exists relatively little theoretical research on the macroeconomics of misgovernance. Our objective in this paper has been to make a contribution towards filling this gap. The model that we have used contains the essential ingredients that public policy is implemented by subordinate officials whose interests conflict with superiors and whose pursuit of these interests entails corrupt practices that impose costs on society as a whole. Our specific focus of attention has been on corruption in public procurement, where bureaucrats exploit their powers of discretion in providing public goods to falsify information and embezzle public funds. The main results of our analysis may be summarised as follows. First, corruption and development are determined jointly in a relationship that is two-way causal: bureaucratic malfeasance both influences and is influenced by economic activity. Second, this two-way causality gives rise to threshold effects and multiple development regimes: there is a low development regime, a high development regime and an intermediate development regime. Third, the equilibrium properties of these regimes are very different: in low stages of development there is a unique equilibrium with high corruption, in high stages of development there is a unique equilibrium with low corruption, and in intermediate stages of development there are both types of equilibrium. Fourth, transition between regimes may or may not be feasible and it is possible for a development trap to occur: corruption and poverty may become permanent fixtures of an economy unless fundamental changes take place. Fifth, corruption distorts both the quantity and quality of public expenditures: these expenditures are not only inflated, but also misdirected towards the provision of low-quality public goods.

The above results do well in explaining a number of empirical observations: corruption is higher in poor countries than in rich countries; corruption is more varied among middle-income countries; corruption can be persistent and may be alleviated only slowly by development; and corruption can compromise development by distorting public expenditures. Based on these insights, we view our analysis as a promising step towards understanding an issue that is dominating the international development arena. 


\section{Appendix}

We establish the existence of a mixed strategy equilibrium in the intermediate development regime. Suppose that, for $k_{t} \in\left(k_{1}^{c}, k_{2}^{c}\right)$, there is a fraction, $\eta \in(0,1)(1-\eta)$, of corruptible bureaucrats who are corrupt (non-corrupt). Proceeding in the usual way, we may derive the following expressions for interest rates and wages:

$$
\begin{gathered}
\bar{r}=(1-\alpha) A l^{\alpha}[1-\eta \nu(1-\gamma)]^{\beta}(s g)^{\beta}, \\
\bar{w}_{t}=\alpha A l^{\alpha-1}[1-\eta \nu(1-\gamma)]^{\beta}(s g)^{\beta} k_{t} \equiv \bar{w}\left(k_{t}\right),
\end{gathered}
$$

The condition for a corruptible bureaucrat to be corrupt is

$$
\frac{(\phi-\theta) s g}{n} \geq(1-p)(1+\bar{r}) \bar{w}_{t} \equiv \bar{h}\left(k_{t}\right)
$$

It is straightforward to verify that, for a given $k_{t}$ and a given $\eta \in(0,1)$, $\widehat{r}>\bar{r}>\widetilde{r}$ and $\widehat{w}_{t}>\bar{w}_{t}>\widetilde{w}_{t}$ so that $\widehat{h}(\cdot)>\bar{h}(\cdot)>\widetilde{h}(\cdot)$. In terms of Figure 1, the curve $\bar{h}(\cdot)$ always lies between the curves $\widehat{h}(\cdot)$ and $\widetilde{h}(\cdot)$. It follows that, within the region $\left(k_{1}^{c}, k_{2}^{c}\right)$, there is a single intersection between $\frac{(\phi-\theta) s g}{n}$ and $\bar{h}(\cdot)$. Consequently, for any given $k_{t} \in\left(k_{1}^{c}, k_{2}^{c}\right)$, there exists an $\eta \in(0,1)$ such that $\frac{(\phi-\theta) s g}{n}=\bar{h}(\cdot)$, implying that each corruptible bureaucrat is indifferent between being corrupt and non-corrupt. This $\eta$ is the fraction of corrupt corruptible bureaucrats that supports a mixed strategy equilibrium. 


\section{References}

[1] Abbott, E., 1988. Haiti: The Duvaliers and Their Legacy. McGraw-Hill, New York.

[2] Acemoglou, D. and T. Verdier, 1998. Property rights, corruption and the allocation of talent: a general equilibrium approach. Economic Journal, 108, 1381-1403.

[3] Acemoglou, D. and T. Verdier, 2000. The choice between market failures and corruption. American Economic Review, 90, 194-211.

[4] Ades, A. and R. Di Tella, 1997. The new economics of corruption: a survey and some new results. Political Studies, 45 (Special Issue), 496515.

[5] Ades, A. and R. Di Tella, 1999. Rents, competition and corruption. American Economic Review, 89, 982-993.

[6] Andvig, J.C. and K.O. Moene, 1990. How corruption may corrupt. Journal of Economic Behaviour and Organisations, 13, 63-76.

[7] Banerjee, A.V., 1997. A theory of misgovernance. Quarterly Journal of Economics, 112, 1289-1332.

[8] Bardhan, P., 1997. Corruption and development: a review of issues. Journal of Economic Literature, 35, 1320-1346.

[9] Barro, R.J., 1990. Government spending in a simple model of endogenous growth. Journal of Political Economy, 98, S103-S125.

[10] Basu, S. and D.D. Li, 1998. Corruption in transition. University of Michigan Business School Working Paper No.161.

[11] Besley, T. and J. McLaren, 1993. Taxes and bribery: the role of wage incentives. Economic Journal, 108, 119-141.

[12] Cadot, O., 1987. Corruption as a gamble. Journal of Public Economics, $33,223-244$.

[13] Carillo, J.D., 2000. Corruption in hierarchies. Annales d'Economie et de Statistique, 10, 37-61.

[14] Ehrlich, I. and F.T. Lui, 1999. Bureaucratic corruption and endogenous economic growth. Journal of Political Economy, 107, 270-293. 
[15] Fisman, R. and R. Gatti, 2002. Decentralisation and corruption: evidence across countries. Journal of Public Economics, 83, 325-345.

[16] Foellmi, R. and M. Oechslin, 2003. Who gains from non-collusive corruption? Working Paper No.142, Insitute for Empirical Research in Economics, Zurich University.

[17] Frechette, G.R., 2001. An empirical investigation of the determinants of corruption: rent. competition and income revisted. Paper presented at the 2001 Canadian Economic Association Meeting.

[18] Gyimah-Brempong, K., 2002. Corruption, economic growth and income inequality in Africa. Economics of Governance, 3, 183-209.

[19] Hardin, B., 1993. Africa: Dispatches from a Fragile Continent. Harper Collins Publishers, London.

[20] Huntington, S.P., 1968. Political Order in Changing Societies. Yale University Press, New Haven.

[21] Husted, B.W., 1999. Wealth, culture and corruption. Journal of International Business Studies, 30, 339-360.

[22] Jain, A.K. (ed.), 1998. The Economics of Corruption. Kluwer Academic Publishers, Massachusettes.

[23] Jain, A.K., 2001. Corruption: a review. Journal of Economic Surveys, 15, 71-121.

[24] Kauffman, D. and S.-J. Wei, 2000. Does "grease money" speed up the wheels of commerce? IMF Working Paper No.WP/00/64.

[25] Keefer, P. and S. Knack, 1997. Why don't poor countries catch up? A cross-national test of an institutional explanation. Economic Inquiry, $35,590-602$.

[26] Klitgaard, R., 1988. Controlling Corruption. University of California Press, Berkeley.

[27] Klitgaard, R., 1990. Tropical Gangsters. Basic Books, New York.

[28] Knack, S. and P. Keefer, 1995. Institutions and economic performance: cross-country tests using alternative institutional measures. Economics and Politics, 7, 207-227. 
[29] Leff, N.H., 1964. Economic development through bureaucratic corruption. American Behavioural Scientist, 8, 8-14.

[30] Leys, C., 1970. What is the problem about corruption? In A.J. Heidenheimer (ed.), Political Corruption: Readings in Comparative Analysis, Holt Reinehart, New York.

[31] Li, H., L.C. Xu and H. Zou, 2000. Corruption, income distribution and growth. Economics and Politics, 12, 155-182.

[32] Mauro, P., 1995. Corruption and growth. Quarterly Journal of Economics, 110, 681-712.

[33] Mauro, P., 1997. The effects of corruption on growth, investment and government expenditure: a cross-country analysis. In K.A. Elliott (ed.), Corruption and the Global Economy, Institute for International Economics, Washington D.C.

[34] Montinola, G.R. and R.W. Jackman, 1999. Sources of corruption: a cross-country study. British Journal of Political Studies, 32, 147-170.

[35] Paldam, M. 2002. The big pattern of corruption, economics, culture and seesaw dynamics. European Journal of Political Economy, 18, 215-240.

[36] Rauch, J.E. and P.B. Evans, 2000. Bureaucratic structure and bureaucratic performance in less developed countries. Journal of Public Economics, 76, 49-71.

[37] Rivera-Batiz, F.L., 2001. International financial liberalisation, corruption and economic growth. Review of International Economics, 9, 727737.

[38] Romer, P.M., 1986, Increasing returns and long-run growth, Journal of Political Economy 94, 1002-1037.

[39] Rose-Ackerman, S., 1975. The economics of corruption. Journal of Public Economics, 4, 187-203.

[40] Rose-Ackerman, S., 1978. Corruption: A Study in Political Economy. Academic Press.

[41] Rose-Ackerman, S., 1999. Corruption and Government: Causes, Consequences and Reform. Cambridge University Press, Cambridge. 
[42] Sachs, J.D. and A.M. Warner, 1997. Sources of slow growth in African economies. Journal of African Economics, 6, 335-376.

[43] Sah, R.K., 1988. Persistence and pervasiveness of corruption: new perspectives. Yale Economic Growth Research Centre Discussion Paper No.560.48.

[44] Sah, R.K., 1991. Social osmosis and patterns of crime. Journal of Political Economy, 99, 1272-1295.

[45] Sarte, P.-D., 2000. Informality and rent-seeking bureaucracies in a model of long-run growth. Journal of Monetary Economics, 46, 173-197.

[46] Shleifer, A. and R. Vishny, 1993. Corruption. Quarterly Journal of Economics, 108, 599-617.

[47] Tanzi, V., 1998. Corruption around the world: causes, scope and cures. IMF Working Paper No.98/63.

[48] Tanzi, V. and H. Davoodi, 1997. Corruption, public investment and growth. IMF Working Paper No.WP/97/139.

[49] Tirole, J., 1996. A theory of collective reputation (with applications to the persistence of corruption and to firm quality). Review of Economic Studies, 63, 1-22.

[50] Treisman, D., 2000. The causes of corruption: a cross-national study. Journal of Public Economics, 76, 399-457. 


\section{Table 1}

\section{Corruption Across Countries}

\begin{tabular}{l|cccc}
\hline Year & 2001 & 2002 & 2003 & 2004 \\
\hline Number of Countries & & & & \\
Total $^{2}$ & 85 & 94 & 121 & 133 \\
Low income & 20 & 24 & 36 & 43 \\
Middle income & 45 & 50 & 65 & 70 \\
Lower middle income & 23 & 29 & 38 & 40 \\
$\quad$ Upper middle income & 22 & 21 & 27 & 30 \\
High income & 20 & 20 & 20 & 20 \\
\hline Range of index & & & & \\
Low income & $1.0-3.4$ & $1.2-3.9$ & $1.3-3.3$ & $1.5-3.6$ \\
Middle income & $2.0-7.5$ & $1.7-6.5$ & $1.6-7.4$ & $1.9-7.4$ \\
Lower middle income & $2.0-5.3$ & $1.7-5.7$ & $1.6-4.9$ & $1.9-5.3$ \\
Upper middle income & $2.8-7.5$ & $2.5-6.5$ & $2.1-7.4$ & $2.3-7.4$ \\
High income & $6.6-9.9$ & $6.3-9.7$ & $6.9-9.7$ & $6.9-9.7$ \\
\hline Variance of index & & & & \\
Low income & 0.33 & 0.36 & 0.23 & 0.24 \\
Middle income & 1.39 & 1.47 & 1.39 & 1.56 \\
Lower middle income & 0.96 & 0.93 & 0.69 & 0.69 \\
Upper middle income & 1.22 & 1.50 & 1.59 & 1.84 \\
High income & 0.95 & 1.09 & 0.88 & 0.80 \\
\hline Coefficient of variation & & & & \\
of index & & & & \\
Low income & 23.47 & 24.73 & 21.23 & 20.52 \\
Middle income & 29.41 & 31.35 & 32.01 & 33.59 \\
Lower middle income & 28.38 & 28.45 & 26.00 & 26.11 \\
Upper middle income & 24.04 & 27.03 & 28.75 & 30.58 \\
Upper income & 11.85 & 12.59 & 11.16 & 10.64 \\
\hline
\end{tabular}

Notes.

1. The range of the corruption index is $0-10$, with lower values indicating higher corruption.

2. Countries that are not classified by the World Bank have been excluded from the sample. In particular instances other countries have been excluded due to questions about the reliability of the data (e.g., Bangladesh in 2001). 
Figure 1

Equilibrium Corruption

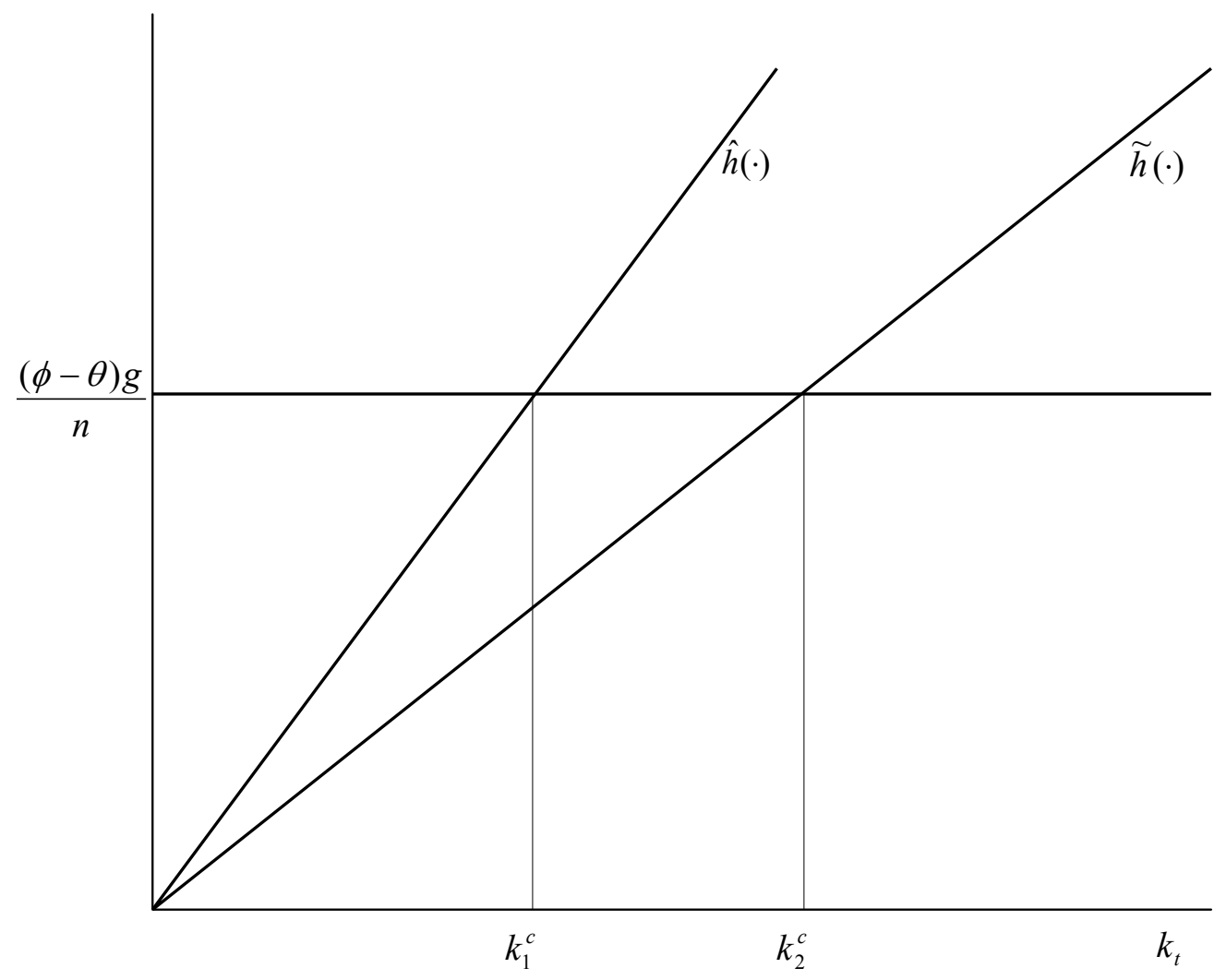


Figure 2

Capital Accumulation

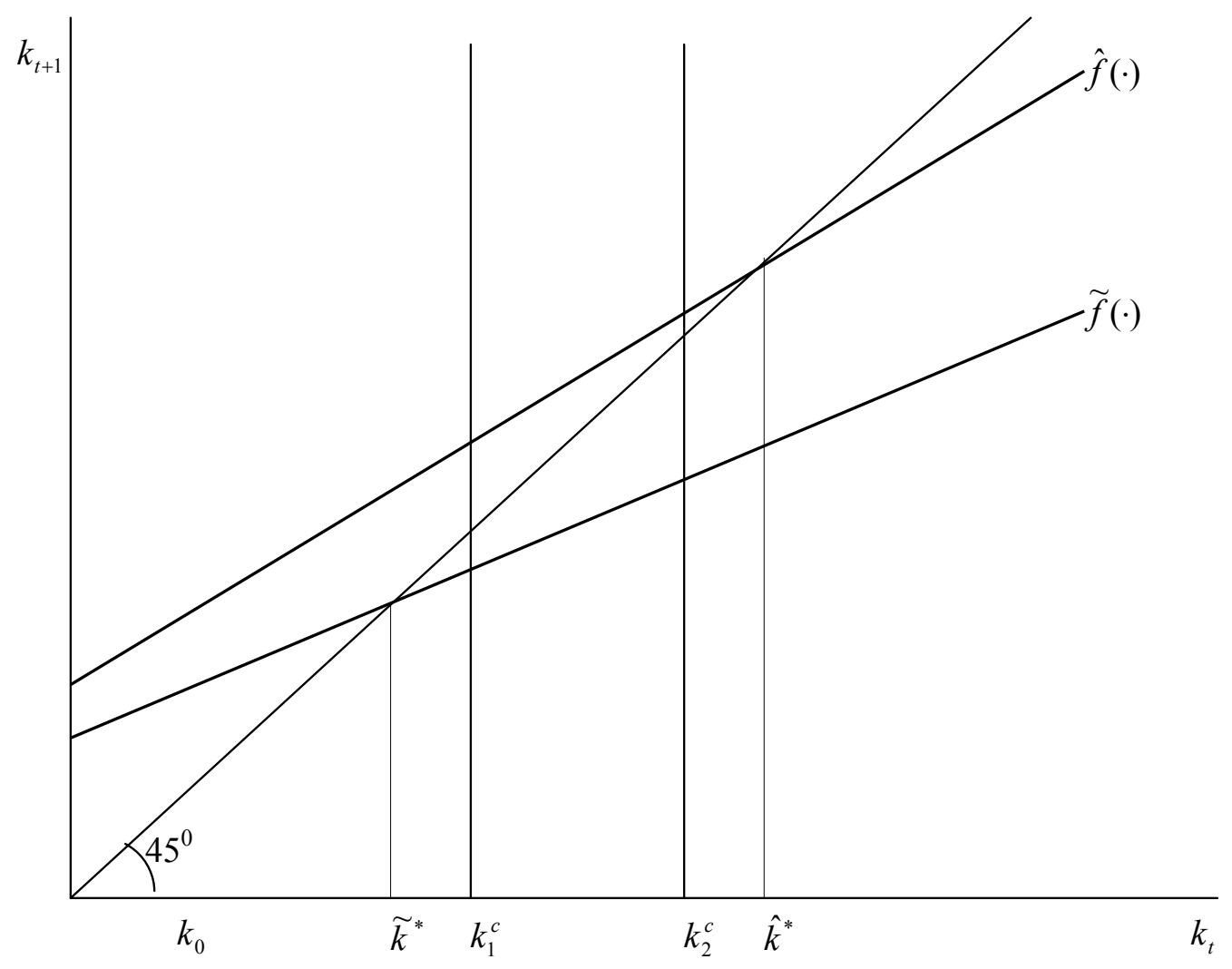

